\title{
CHALLENGES OF DESIGNING REMOTE COMMUNITIES IN EQUATORIAL AFRICA: OKOLASSI EXAMPLE
}

DOI: 10.18485/arh_pt.2020.7.ch55

\section{_ Dejan Vasović \\ Assistant Professor, University of Belgrade - Faculty of Architecture, Bulevar kralja Aleksandra 73/II, 11000 Belgrade, Serbia, d.vasovic@arh.bg.ac.rs}

\section{_ Ruža Okrajnov Bajić}

Assistant Professor, University of Belgrade - Faculty of Architecture,

Bulevar kralja Aleksandra 73/II, 11000 Belgrade, Serbia, ruza@arh.bg.ac.rs

\section{_ Darko Pavićević}

Teaching Assistant, University of Belgrade - Faculty of Architecture, Bulevar

kralja Aleksandra 73/II, 11000 Belgrade, Serbia, darko.pavicevic@arh.bg.ac.rs

\section{_ Goran Gogov}

Cabinet 2G, Immeuble Diamant II, BP 1140,

Libreville, Gabon, info@cabinet2g.com

\section{ABSTRACT}

Developing countries in Africa are facing numerous challenges in the process of constructing new settlements in the remote areas. Most of the construction activities are performed in the big cities, encouraging major migrations from all sides of country to the dense urban areas. Developing new settlements on the outskirt of the city is the only way to prevent its collapse. However, these areas have no infrastructure needed for the purpose.

The paper will present the case study of the construction challenges during the design and construction of the new settlement in Okolassi, local community $30 \mathrm{~km}$ distant of the capital Libreville. Different challenges like poor road infrastructure, lack of electricity, water and sewage, or non-existence of the skilful workforce, could transform even the simplest construction task in the insurmountable problem. Careful planning and designing are essential for the successful procurement and construction in the rainforest environment.

KEYWORDS _ remote communities, developing countries, construction of settlements

\section{INTRODUCTION}

One of the most challenging issues in developing countries, if not in all, is to provide dissent but affordable living conditions for the fast growing population. Looking for the job and better life perspectives, majority of population migrate to the big cities. Urban infrastructure is developing more slowly compared to the increase of the population, bringing capital cities to the edge of the collapse. As a continent with the highest rate of the population increase, Africa is a challenging experimental polygon desperately seeking for new solutions.

Gabon is an African country, lying on the west coast of Africa, intersected by the Equator. With the population of more than 2.23 million people (2020. est., 146 th in the World), $2.5 \%$ population growth 
rate (2020. est., 22 nd in the World), with almost $90 \%$ of the inhabitants living in the cities, and more than $58 \%$ of the population under than age of 25 , Gabon is forced to find the solutions for the growing housing problem.

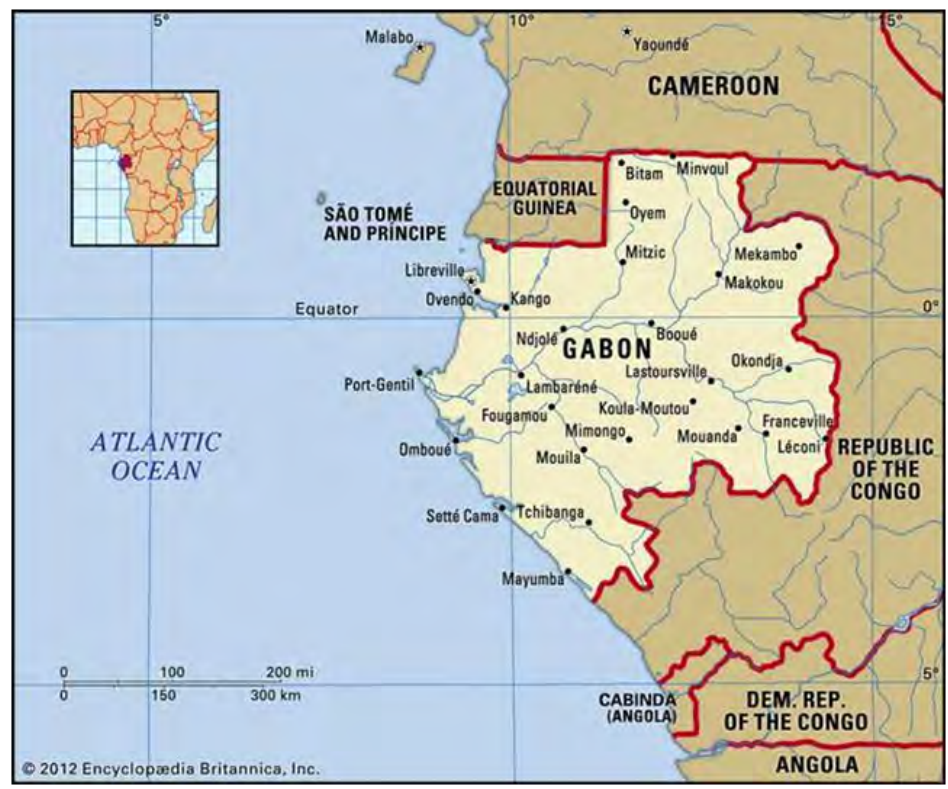

_ Figure 1: Gabon - political map (source: Encyclopaedia Britannica)

As a former French colony, Gabon and capital Libreville have a respectable urban planning and architectural heritage. However, decades of planning and construction negligence formed large informal settlements and slums around the city, blocking the continuous urban development. The only way to overcome this problem is to overpass the congested periphery of the city, and form new, satellite settlements on the capital outskirts, along the main roads.

Small village Okolassi is lying on the national road, which leads to central Gabon, $30 \mathrm{~km}$ from the centre of the capital Libreville. Remote position, dense tropical forest and lack of infrastructure saved hundreds of hectares of land from the devastation and misuse. About 25 ha of the forest land for the first phase, and up to 100 ha in the second phase, was determined for the construction of the new Okolassi settlement for more than 5,000 people. Private developer acquired the land and delegated the contract for the planning, design and construction development to the team of Serbian and Gabon architects. In this paper, the planning and designing process for the construction of the Okolassi settlement is presented. The Challenges and the faults of the planning process for the construction at $8,000 \mathrm{~km}$ distant location, in the heart of the dense rainforest, are discussed.

\section{OBTAINING VALID INPUT FOR THE VALID DESIGN DECISIONS}

Design and build form of the construction process is worldwide practice. Key for the success is to make right long-term tenable decisions at the early stages of the design, when architect has insufficient information. It is well known fact that the quality of the outcoming result highly depend of the accuracy and quality of the input data. However, the challenge is to define a method for the decision-making at the early stages of design that will provide efficient and profitable construction. Designing for the Investor and a plot far away, at the other continent, different climate and environmental zone, diverse social, cultural and urban heritage, demands profound preparation. Previous 
experience and focus on the most important data is of the essence for the success of the project.

\section{Land, climate and environment based decisions}

Determination of the general programme for the Okolassi settlement should have begun with thorough, detail and precise collection of information about environment, people, needs, market, etc. Gabon (officially Gabonese Republic) lies on the west coast of central Africa, bordered by Equatorial Guinea and Cameroon on the north, Republic of Congo on the east and south, and Gulf of Guinea on the west. Gabon has 2.23 million inhabitants on 257,667 sq. $\mathrm{km}$ ( 8.7 inhabitants per sq. km; it makes Gabon one of the least densely populated countries on earth.). Almost $90 \%$ of the people live in the cities, nearly $40 \%(824,000)$ in capital Libreville.

Climate in Gabon is equatorial, with high humidity and temperatures year-round, and varies so little throughout the year (humidity $80-90 \%$, temperatures between $20-30{ }^{\circ} \mathrm{C}$ ).

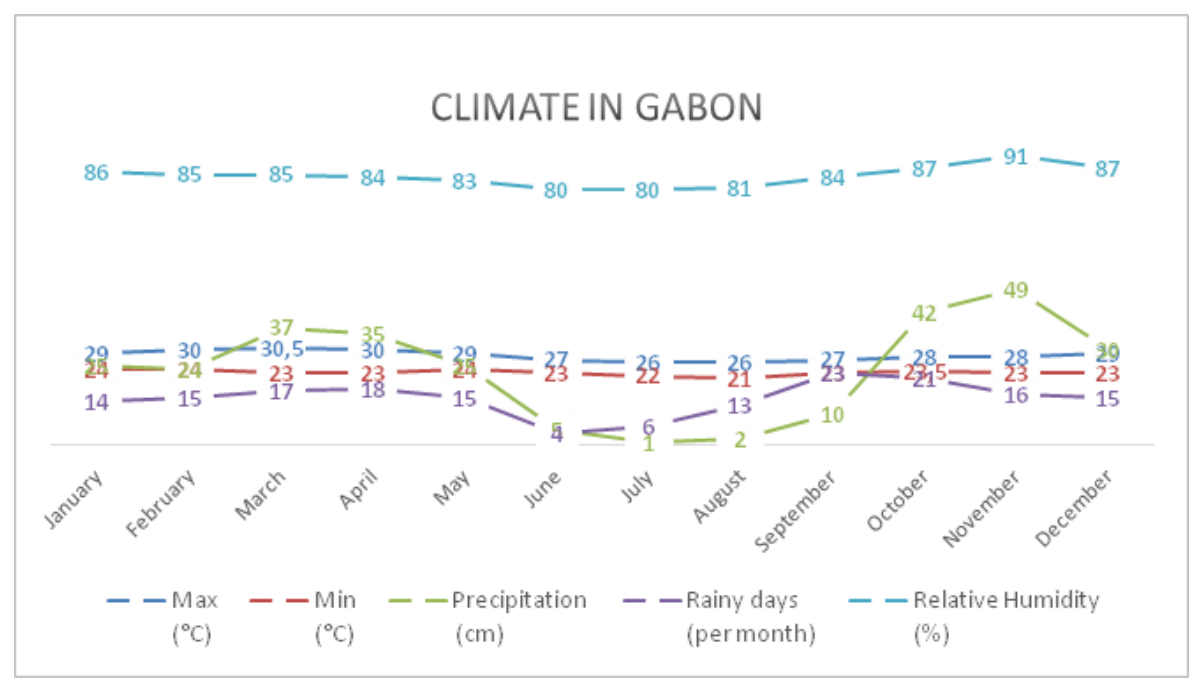

_. Figure 2: Climate graph for Ntoum, 35 km from Libreville, Gabon - (source: various)

Equatorial climate is characterised by humid and hot climate with heavy rains, varying from an annual average of $3,050 \mathrm{~mm}$ at Libreville to $3,810 \mathrm{~mm}$ farther north on the coast. However, precipitation varies significantly throughout the year, with almost all of it raining between September and May. Number of rainy days that are $4-5$ in June and July goes up to $22-23$ in September and October. That means half of the year are rainy days (177 days on average). From June to beginning of September there is virtually no rain but high humidity. In addition, there are occasional rains in December and January. During the remaining months, rainfall is excessive, "caused by the condensation of moist air resulting from the meeting, directly off the coast, of the cold Benguela Current from the south and the warm Guinea Current from the north."

Congo basin is the second largest block of contiguous tropical rainforest after the Amazonian ba$\sin$. The analysis made by using the satellites, "estimate that the total lowland humid and swamp forest area for Africa is 1,998,290 km2, of which $89.3 \%$ is in Central Africa, $6.0 \%$ in West Africa, $2.2 \%$ in Madagascar and $2.4 \%$ in Eastern Africa. In terms of countries, the Democratic Republic of Congo (DRC) is the forest giant, accounting for $53.6 \%$ of Africa's lowland rainforest area, followed by Gabon (11.2\%), the Republic of Congo (10.4\%) and Cameroon (10.0\%). The remaining countries account for $14.8 \%$ of total lowland rainforest area." Throughout Gabon, tropical rainforest cover more than $87 \%$ of the land, and practically, there are no large savannah but areas with forest patches on plateaus. There are more than 10 ha of the forest per capita in Gabon. 


\section{Relief and drainage}

Gabon is situated along the Atlantic Ocean. Therefore, coastal relief is plain, narrow (less than 30 $\mathrm{km}$ wide), and formed of sand and alluvium. Strong Benguela Current with the influence of large Ogooué River estuary deteriorates Gabon's coastline by creating sandbars. In the continental part of the country, there is a vast Ogooue River basin covered with the dense rainforest. Geologically, this basin is formed by series of granite-based plateaus, spreading from west to southeast, rising to $300-600$ meters. The Ogooué River, together with several big rivers (Okano, Ngounié, Komo ...) drains the majority of Gabon territory.

\section{Transportation}

Transportation is one of the Gabon's weak points that strongly influence economic development. Maritime transport is the dominant type of transport for the import of the goods. The main international ports are located at Port-Gentil and Owendo (Libreville). However, inland transport is a problem. The Ogooué River is navigable from the Atlantic (Port-Gentil) to Ndjolé, 150 miles (240 km) upstream.

Until the 1970s, Gabon had no railroads. In 1974, the construction of the Transgabon (Transgabonais) Railroad from Owendo (Libreville) to Francevile $(936 \mathrm{~km}$ ) started in three sections: to Ndjolé (opened in 1979), to Booué (opened in 1983), and finaly to Francevile (opened in 1986). Railway is mainly used for transport of the bulk cargo: petrol, ore, logs and other goods from and to deep inland. These are the reasons why almost everything else is transported by trucks and lorries. Nevertheless, to build, and especially to maintain roads in these climate conditions is a challenging task. However, road network is very modest, often deteriorated by heavy rains and slides. There is only one road - called National road - from capital Libreville to inland, and not even one from the second largest city in Gabon, Port-Gentil.

Passenger transport is mainly by air. In 2002, Gabon had almost sixty airports, ten of which had paved runways, and three of them are international airports: Libreville (Leon M'Ba), Port-Gentil, and Franceville.

\section{Local infrastructure networks}

Gabon's electricity production meets more than $85 \%$ of its needs. The production is based on natural gas from the fields at Port-Gentil - $51 \%$, and on hydropower (Tchimbélé, Kinguélé, and Poubara complexes) - 49\%. At the Libreville surroundings, electrical grid is well developed along the National road, but blackouts are not rare. Gabon is rich in water, but the water supply grid is developed in the bigger cities. Almost everywhere is possible to bore a well, but the people usually drink bottled water. Sewage is rudimental and underdeveloped, even in the capital.

\section{OKOLASSI SETTLEMENT - DESIGN CONSTRAINTS}

Those facts were very important for the program defining of the Okolassi settlement, and crucially influenced the programme designing decisions. On the basics of those facts, decision was made to start the construction of the plot with access on the National road, closest to the Libreville, because there was some existing infrastructure. It was planned to provide water locally, by boring the well. Sewage grid should have been built locally and sewage water treated (Gabon laws are very strict regarding this matter, so it was planned to build the water-treatment plant in the first phase).

Predominant type of housing is single-family housing for growing families (having in mind that average fertility rate is 3.41 child per woman). Size of plots and houses were designed carefully, to allow the possibility to extend the buildings with additional bedrooms, as the family grow up. Once defining the families as a principal Okolassi settlement occupants group, a necessity for the social amenities constructed in the first phase, raised as a must. Therefore, programme was enriched with the market, small shopping mall, and a gas station, as well as a kindergarten and a school. Parcels for a church and a mosque were also planned. However, because of the proximity of the Tax-free 
economic zone and its employs' demand for the nearby flats, two apartment buildings were included in the program and designed in the first phase.

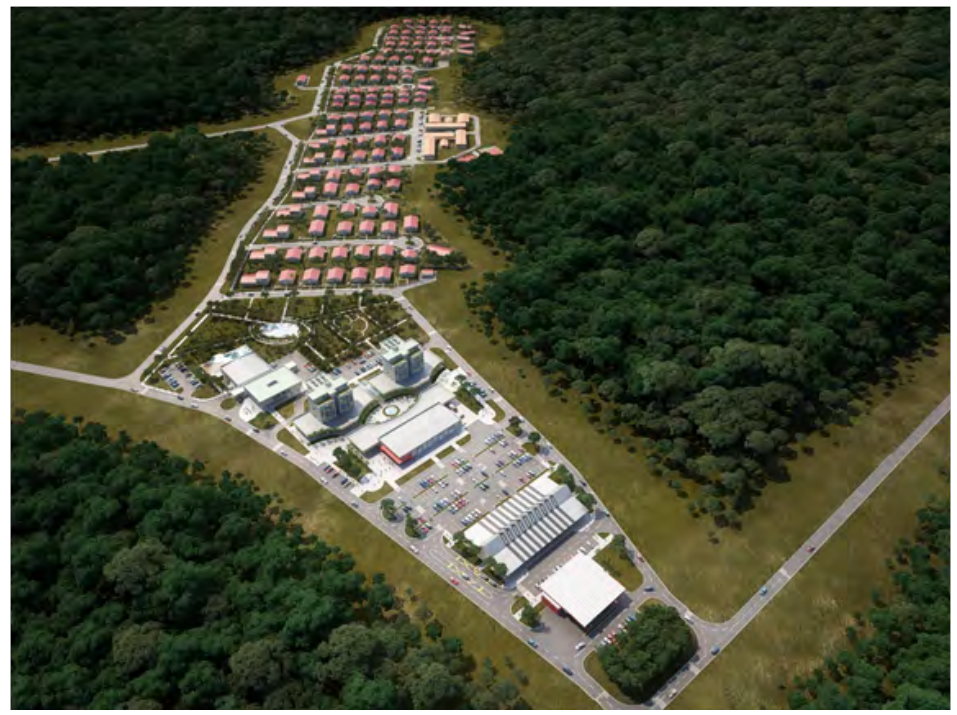

_ Figure 3: Arial view of new Okolassi settlement (3D render of the first phase)

Rainfall was the most influential parameter for the construction. As the design process started in May, at the end of the rainy (sunny) season, in order to begin the construction process over the ongoing year, it was of the ultimate importance to start with the ground works during the dry (cloudy) season at the mid June. Whole plot was covered with dense and high rainforest, so the geological excavation and survey weren't performed before the planning and design. Therefore, zoning and planning of the settlement, as well as the design of the most of the buildings (not only houses, but also school, market, apartment buildings, church and mosque as well) was performed "blindly", solely relying on the previous experience and rare photographs. Fortunatelly, everything more or less fitted well except the positions of the school and the kindergarten: it was impossible to make regular access, without the displacement of the nine meters of soil from the top of the hill. Removed soil was used for the embankment throughout the plot.
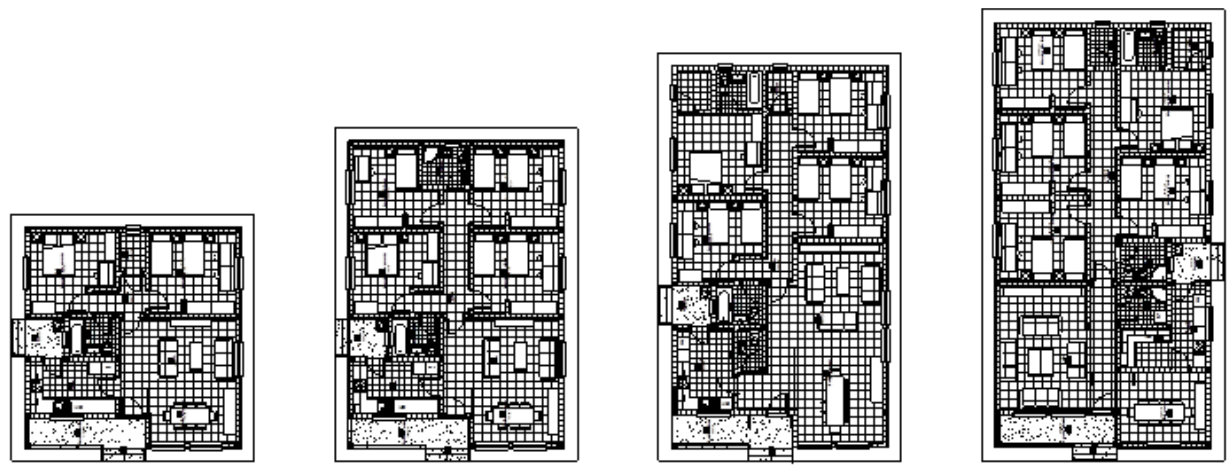

Figure 4: Okolassi houses types (expandable house - two bedroom to five bedroom - first phase) 


\section{OKOLASSI SETTLEMENT - CONSTRUCTION CONSTRAINTS}

During the design process, lot of time was spent to foreseen the problems inherent to the construction. However, it was not possible to predict everything, but the complications were diminished to an acceptable level. The main challenges during the construction phase were logistic: procurement and transport of the materials to the construction site.

The time schedule was tight: to construct thirty houses, a market and a school for 90 days. It was very important to use local materials, but there were just few of the possible providers. Local sand appeared to be very muddy, acceptable for the infill and rendering, but inappropriate for the concrete production. Instead, the granite aggregate had to be used. That increased the transportation cost and time, but at the same time increased the quality of the concrete to the level that some concrete construction elements` dimension were minimised.

Due to heavy rainfalls, site traffic was complicated. Site roads intensively eroded, so the only way to transport material to the construction sites was to use telescopic forklifts. As this problem was foreseen during the designing phase, two telescopic forklifts were imported from Italy before the construction started. The equipment were very useful for some other purposes, including assembly of the steel construction.

One of the problems that aroused during the construction was the situation when preselected local steel construction provider withdraw from the project. It was not possible in Gabon to provide steel structure for the construction of the market, so decision was made to purchase it in Serbia. Direct consequence of that decision was detailed adaptation of the design, in order to provide appropriate dimensions of the structural elements for the maritime transport in ship containers. Maritime transport of the heavy steel elements provided an opportunity to transport it together with bulky material from Serbia (water and sewage pipes, insulation etc.). Another problem appeared when the locally leased crane for the assembly of the construction, broke down. Assembly of the steel structure was executed with two telescopic forklift, used for the lifting the concrete blocks and roof tiles for the construction of the houses. All of those increased the costs and prolonged the construction time, but did not influence the date of completion.
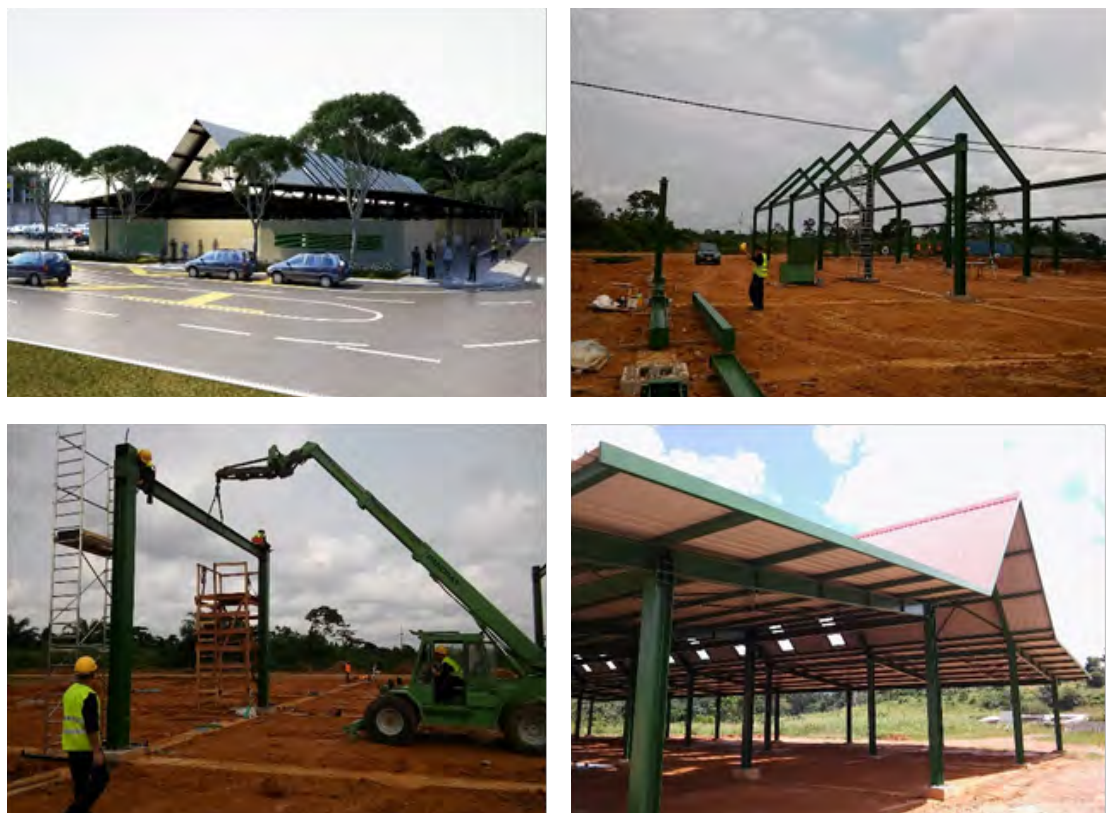

_ Figure 5: 3D render of the Okolassi market, construction phases and assembled structure. 


\section{CONCLUSIONS}

In the time shortage and tight schedule for the construction, quality decisions made during planning and design phase is crucial. At the remote sites, no one can expect to avoid the problems. Therefore, good preparation, procurement of the material, quality and motivation of the workforce, as well as its capability for improvisation, makes the difference between the success and fail. Some of the recommendations, based on the Okolassi case, should be:

1. It is essential to collect all available information on the climate, relief and vegetation of the area being worked on;

2. Transport possibilities should be studied thoroughly to make a precise plan for the transport of people, materials and equipment;

3. Planning should be well-ahead: it should be kept in mind that it may take several weeks to carry out any activity;

4. Inquire about the available local workforce; also invetigate the possibility of accommodating non-local workforce;

5. It is useful to create variant solutions in advance, for each activity, in order to adapt to changes in situ;

6. It is necessary to make quick and timely decisions, but also to be prepared for surprises.

\section{REFERENCES}

_ Mulène, Remy. 2002. Le Gabon Aujourd hui. Paris, Editions du Jaguar.

- Michael Majale, Graham Tipple, Matthew French and Remy Sietchiping, 2012. Affordable Land and Housing in Africa, United Nations Human Settlements Programme (UN-HABITAT) Nairobi, Kenya, https:// unhabitat.org/.

- Walters, Gretchen, Parmentier Ingrid and Stévart Tariq. 2012. "Diversity and conservation value of Gabon's savanna and inselberg open vegetation: An initial gap analysis." Plant Ecology and Evolution 145 (1): 46-54, 2012 http://dx.doi.org/10.5091/plecevo.2012.606

_ Cuni-Sanchez A, White LJT, Calders K, Jeffery KJ, Abernethy K, Burt A, et al. 2016. "African Savanna-Forest Boundary Dynamics: A 20-Year Study." PLoS ONE 11(6): e0156934. doi:10.1371/ journal.pone.0156934

- Gond V, Fayolle A, Pennec A, Cornu G, Mayaux P, Camberlin P, Doumenge C, Fauvet N, Gourlet-Fleury S. 2013. "Vegetation structure and greenness in Central Africa from Modis multi-temporal data." Phil Trans $R$ Soc B 368: 20120309. http://dx.doi.org/10.1098/rstb.2012.0309

_ Oslisly R, White L, Bentaleb I, Favier C, Fontugne M, Gillet J-F, Sebag D. 2013. "Climatic and cultural changes in the west Congo Basin forests over the past 5000 years." Phil Trans R Soc B 368: 20120304. http://dx.doi.org/10.1098/rstb.2012.0304

- Malhi Y, Adu-Bredu S, Asare RA, Lewis SL, Mayaux P. 2013. "African rainforests: past, present and future." Phil Trans R Soc B 368: 20120312. http://dx.doi.org/10.1098/rstb.2012.0312

_ Cia World Factbook, 2020. "Africa:Gabon", Accessed February 15, 2020. https://www.cia.gov/library/ publications/the-world-factbook/geos/print_gb.html

- Encyclopaedia Britannica, 2020. "Gabon", Accessed February 10, 2020.Last modified August 22. https:// www.britannica.com/place/Gabon

_ Nations Encyclopedia, 2020. "Gabon", Accessed February 11, 2020. Last modified 2019. https://www. nationsencyclopedia.com/Africa/Gabon-CLIMATE.html

- Weather-and-climate. 2020 "Climate in Libreville, Gabon." Accessed February 14, 2020. https://weather-and-climate.com/average-monthly-Rainfall-Temperature-Sunshine-fahrenheit,Libreville,Gabon

- Weatherspark. 2020. “Average-Weather-in-Ntoum-Gabon". Accessed February 14, 2020.

- https://weatherspark.com/y/61792/Average-Weather-in-Ntoum-Gabon-Year-Round

_ WorldData.info. 2020. "The Climate in Gabon." Accessed February 14, 2020. https://www.worlddata. info/africa/gabon/climate.php 